\title{
Does Age Matter in Elder Patients Over 80 Years Undergoing Coronary
} Artery Bypass Grafting

\section{Taner lyigun $^{1 \star}$, Mugisha Markior Kyaruzi ${ }^{1}$, Adem Reyhancan ${ }^{1}$, Bariş Timur ${ }^{1}$, Mehmet Kaya ${ }^{1}$ and Muzeyyen lyigun ${ }^{2}$}

${ }^{1}$ Department of Cardiovascular Surgery, Istanbul Mehmet Akif Ersoy Thoracic and Cardiovascular Surgery Training and Research Hospital, Istanbul, Turkey

${ }^{2}$ Department of Anesthesiology, Acibadem University Hospital, Istanbul, Turkey

"Corresponding author: Taner lyigun, Department of Cardiovascular Surgery, Istanbul Mehmet Akif Ersoy Thoracic and Cardiovascular Surgery Training and Research Hospital, Istanbul, Turkey, Tel: 902126922000; Fax: 902124719494; E-mail: taneriyi@gmail.com

Received: June 24, 2018; Accepted: July 24, 2018; Published: July 26, 2018

Copyright: () 2018 lyigun T, et al. This is an open-access article distributed under the terms of the creative commons attribution license, which permits unrestricted use, distribution, and reproduction in any medium, provided the original author and source are credited.

\section{Abstract}

Background: Coronary artery disease remains the most common cause of death in developing nations. Despite the associated risks of open cardiac surgery in elder patients, coronary artery bypass grafting (CABG) remains the gold Standard in treatment of patients with multiple coronary lesions. Many studies have been done to clearly determine the risks associated with early mortality after CABG in elderly patients.
\end{abstract}

Aim: To reveal the clinical experience of our center on the risks associated with mortality and morbidity in patients over 80-years-old who undergo isolated CABG.

Study design: Retrospective study.

Method: Our retrospective study consisted of 85 patients aged over 80-years who had undergone isolated coronary artery bypass grafting between January 2010 to July 2017 at our center. In this retrospective study, preoperative characteristics, operative data and postoperative outcomes were reviewed in relation to early and late mortality.

Results: Our study consisted of 85 elder patients. The mean age was $82.11 \pm 2.51$ years old. Early mortality was significantly higher in patients whose preoperative creatinine level was high and patients who had high level of blood transfusion (erythrocyte). No significant statistical outcome was found in patients who had early mortality in terms of preoperative hemoglobin level, cross clamping time (CCT), cardiopulmonary bypass time (CPB), body mass index (BMI) value, intensive care unit time, Ejection Fraction (\%), duration of hospitalization, EuroSCORE, wound infection rate, pleural effusion rate, cerebrovascular event rate, Diabetes Mellitus (DM) rate and hypertension rate. Relevantly these factors were also associated with late mortality.

Conclusion: Preoperative high creatinine level and massive blood transfusion are associated with early and late mortality in elder patients undergoing isolated coronary artery bypass grafting.

Keywords: Coronary artery bypass grafting; Creatinine; Blood transfusion; Elder patients

\section{Introduction}

Coronary artery disease remains the most common cause of death in developing nations. Despite the associated risks of open cardiac surgery in elder patients, coronary artery bypass grafting (CABG) remains the gold Standard in treatment of patients with multiple coronary lesions. Many studies have been done to clearly determine the risks associated with early mortality after CABG in elderly patients $[1,2]$.

Risk determining scores (i.e. EuroSCORE, STS score) were set to allow the institutional quality control and epidemiology analysis. Scores also enable surgeons to predict preoperative, perioperative and postoperative risks for properly informing patients on the consequences associated with CABG in elderly patients. Despite improvement of risk stratification score over the last decades, recent studies question their applicability because they tend to overestimate the mortality rate in the general population and underestimate the mortality in high risk populations $[3,4]$.

Clinical manifestation of Coronary Artery Diseases (CAD) in elderly patient is more complex compared to younger patients. Comorbidities in elderly patients may mask the symptoms of even severe CAD and therefore presenting with atypical symptoms making diagnosis more difficult. Also, association of comorbidities with aging makes treatment of these elder patients to be challenging.

Aging is not contraindicated for CABG, but the risks associated with age makes the procedure to be more challenging [5-7]. During preoperative assessment, evaluation of organ functions such as renal functions, hematological changes and other organ functions determines the risk that may affect the mortality and morbidity in these patients. On the other hand, surgical revascularization not only benefits quality of life but may also improve long-term survival in this patient population [8]. 
The aim of our study was to reveal the clinical experience of our center on the risks associated with early and late mortality in patients over 80-years-old who undergo isolated CABG.

\section{Materials and Methods}

Our retrospective study consisted of 85 ( 35 females and 50 males) patients aged over 80 -years who undergone isolated CABG at our center from January 2010 to July 2017. Our results were evaluated in terms of preoperative, perioperative and postoperative data including their early and late mortality. Early mortality was defined as the death that occurs within 30 days post operatively. The operative risk was evaluated using the European System for Cardiac Operative Risk Evaluation (EuroSCORE I) which included age, gender, left ventricular ejection fraction, presence of chronic obstructive pulmonary disease (COPD), diabetes mellitus (DM), hypertension (HT), previous cerebral vascular event (CVE), preoperative serum creatinine level, critical preoperative status or emergent surgery, infection, smoking, cross clamping time, cardiopulmonary bypass time, number of coronary artery lesions, inotrope use, intra-aortic balloon pump (IABP) use, hospital stay, intensive care unit stay, use of erythrocyte suspension, pleural effusion, revision, atrial fibrillation, acute renal failure (ARF) and chronic renal failure (CRF).

Cardiac markers such as troponin and inflammatory biomarkers are not routinely measured in elective cases in our hospital. Patients with unstable angina pectoris (USAP) have an emergency operation before the increase of troponin levels. Therefore, these biomarkers are not included in the study because they have no statistical significance.

\section{Statistical method}

Mean, standard deviation, median lowest, highest, frequency and ratio values were used in the descriptive statistics of the data. The distribution of the variables was measured by the Kolmogorov smirnov test. Mann-Whitney test was used in the analysis of quantitative independent data. Chi-square test was used for analysis of qualitative independent data, and Fischer test was used when chi-square test conditions were not met. The level of influence was investigated by univariate and multivariate logistic regression. SPSS 22.0 program was used in the analyzes.

\section{Results}

General characteristics of our patient's population is summarized in Table 1. The age and gender distribution of the patients in the group with and without mortality did not differ significantly ( $p>0.05)$. In the group with mortality, preoperative, postoperative creatinine level was significantly higher $(\mathrm{p}<0.05)$ than non-mortality group. The mortality within period of our study occurred in 21 patients (6 in females and 15 in males). In the group with mortality, the amount of erythrocyte suspension and the plasma/platelet suspension were significantly higher $(p<0.05)$ than the non-mortality group. In the group with and without mortality, preop hemoglobin value, CCT, CPB time, BMI, ICU stay, $\mathrm{EF} \%$, duration of hospitalization, EuroSCORE, wound infection rate, pleural effusion rate, CVE rate, DM rate, $\mathrm{HT}$ rate, IABP, ratio of LIMA-LAD, ratio of AO-LAD, ratio of LIMA-D1, ratio of AO-D1, ratio of $\mathrm{AO}-\mathrm{D} 2$, ratio of $\mathrm{AO}-\mathrm{IM}$, ratio of $\mathrm{AO}-\mathrm{OM} 1$, ratio of $\mathrm{AO}-\mathrm{OM}$, ratio of AO-CX, AO-RCA ratio, AO-PL ratio, AO-PD ratio were not different $(p>0.05)$. The duration of hospitalization in the group with mortality was significantly higher $(\mathrm{p}<0.05)$ than in the group without mortality. In the group with mortality, revision rate, ARF-CRF ratio and inotropic usage rate were higher than non-mortality group $(\mathrm{p}<0.05)$ (Table 2).

\begin{tabular}{|c|c|c|c|c|c|}
\hline \multicolumn{2}{|c|}{ Characteristics } & Min-Max & Median & Mean $\pm s . d / n$ & $\%$ \\
\hline \multicolumn{2}{|l|}{ Age } & $80-91$ & 81 & $82.11 \pm 2.51$ & -- \\
\hline \multirow[t]{2}{*}{ Sex } & Female & -- & -- & 35.00 & $41.20 \%$ \\
\hline & Male & -- & -- & 50.00 & $58.80 \%$ \\
\hline \multicolumn{6}{|c|}{ Creatinine (mg/dl) } \\
\hline \multicolumn{2}{|c|}{ Preop } & $0.6-2.1$ & 1 & $1 \pm 0.3$ & -- \\
\hline \multicolumn{2}{|c|}{ Postop } & $0.5-5$ & 1.3 & $1.41 \pm 0.7$ & -- \\
\hline \multicolumn{2}{|c|}{ Erythrocyte suspension } & $0-19$ & 5 & $5.98 \pm 3.8$ & -- \\
\hline \multicolumn{2}{|c|}{ FFP/Thrombocyte suspension } & $0-27$ & 3 & $5.32 \pm 6.05$ & -- \\
\hline \multicolumn{2}{|c|}{ Preop HG (g/dl) } & $8.9-15.3$ & 12.6 & $12.45 \pm 1.32$ & -- \\
\hline \multicolumn{2}{|c|}{ Cross clamping Time (min) } & $0-168$ & 38 & $37.88 \pm 24.24$ & -- \\
\hline \multicolumn{2}{|c|}{ CPB Time (min) } & $0-218$ & 78 & $75.73 \pm 38.62$ & -- \\
\hline \multicolumn{2}{|l|}{ BSA } & $1.3-3.7$ & 1.8 & $1.79 \pm 0.27$ & -- \\
\hline \multicolumn{2}{|c|}{ ICU stay (day) } & $0-10$ & 1 & $1.68 \pm 1.79$ & -- \\
\hline \multicolumn{2}{|l|}{$E F \%$} & $30-65$ & 55 & $51.65 \pm 10.01$ & -- \\
\hline \multicolumn{2}{|c|}{ FEV1/FVC\% } & $54-99$ & 80 & $78.48 \pm 9.6$ & -- \\
\hline
\end{tabular}


Citation: Iyigun T, Kyaruzi MM, Reyhancan A, Timur B, Kaya M, et al. (2018) Does Age Matter in Elder Patients Over 80 Years Undergoing Coronary Artery Bypass Grafting. J Cardiovasc Dis Diagn 6: 329. doi:10.4172/2329-9517.1000329

Page 3 of 8

\begin{tabular}{|c|c|c|c|c|}
\hline Hospital stay & $3-102$ & 7 & $11.05 \pm 14.63$ & -- \\
\hline EuroSCORE & $3.5-28.8$ & 6.5 & $7.21 \pm 3.55$ & -- \\
\hline wound infection & -- & -- & 3.00 & $3.50 \%$ \\
\hline Pleural effusion & -- & -- & 6 & $7.10 \%$ \\
\hline CVE & -- & -- & 3 & $3.50 \%$ \\
\hline Revision & -- & -- & 8 & $9.40 \%$ \\
\hline ARF.CRF & -- & -- & 5 & $5.90 \%$ \\
\hline $\mathrm{DM}(\mathrm{mg} / \mathrm{dl})$ & -- & -- & 28 & $32.90 \%$ \\
\hline $\mathrm{HT}(\mathrm{mm}-\mathrm{Hg})$ & -- & -- & 47 & $55.30 \%$ \\
\hline Inotrope use & -- & -- & 11 & $12.90 \%$ \\
\hline IABP & -- & -- & 2 & $2.40 \%$ \\
\hline Smoking & -- & -- & 26 & $30.60 \%$ \\
\hline COPD & -- & -- & 17 & $20 \%$ \\
\hline AF Rhythm & -- & -- & 14 & $16.50 \%$ \\
\hline Emergency & -- & -- & 23 & $27.10 \%$ \\
\hline LIMA-LAD & -- & -- & 47 & $55.30 \%$ \\
\hline AO-LAD & -- & -- & 38 & $44.70 \%$ \\
\hline LIMA-D1 & -- & -- & 5 & $5.90 \%$ \\
\hline AO-D1 & -- & -- & 18 & $21.20 \%$ \\
\hline AO-D2 & -- & -- & 4 & $4.70 \%$ \\
\hline AO-IM & -- & -- & 9 & $10.60 \%$ \\
\hline AO-OM1 & -- & -- & 42 & $49.40 \%$ \\
\hline AO-OM2 & -- & -- & 19 & $22.40 \%$ \\
\hline $\mathrm{AO}-\mathrm{CX}$ & -- & -- & 2 & $2.40 \%$ \\
\hline AO-RCA & -- & -- & 18 & $21.20 \%$ \\
\hline AO-PL & -- & -- & 8 & $9.40 \%$ \\
\hline AO-PD & -- & -- & 45 & $52.90 \%$ \\
\hline
\end{tabular}

Table 1: General characteristics and distribution of our study population.

In early mortality evaluation, age and gender distribution of patients were not significantly different $(\mathrm{p}>0.05)$ in patients with and without early mortality. Early mortality was observed only in five patients (3 in females and 2 in males). The preoperative creatinine values of the patients with and without early mortality did not differ significantly $(p>0.05)$. Postoperative creatinine value was significantly higher in the early mortality group than in the non- early mortality group $(\mathrm{p}<0.05)$. In the early mortality group, the amount of blood erythrocyte suspension and plasma/platelet suspension were significantly higher $(p<0.05)$ than in the non-early mortality group. The preoperative hemoglobin value, cross clamping time, CPB time, BSI value, ICU stay,
EF\%, duration of hospitalization, EuroSCORE, wound infection rate, pleural effusion rate, $\mathrm{CVE}$ rate, $\mathrm{DM}$ rate, $\mathrm{HT}$ rate, $\mathrm{AO}-\mathrm{IM}$ ratio, $\mathrm{AO}$ IM ratio, AO-D1 ratio, AO-D2 ratio, LIMA-D1 ratio, LIMA-D1 ratio, IABP ratio, smoking rate, $\mathrm{COPD}$ rate, $\mathrm{AF}$ rhythm rate, $\mathrm{AO}-\mathrm{IM} 2$ ratio, $\mathrm{AO}-\mathrm{CX}$ ratio, $\mathrm{AO}-\mathrm{ECA}$ ratio, $\mathrm{AO}-\mathrm{PL}$ ratio, $\mathrm{AO}-\mathrm{PD}$ ratio were not different $(p>0.05)$. The duration of hospitalization in the early mortality group was significantly higher $(p<0.05)$ than in the non-early mortality group. In the early mortality group, the revision rate, ARB$\mathrm{CRF}$ ratio and inotropic utilization rate were significantly higher $(\mathrm{p}<0.05)$ than in the non-early mortality group (Table 3$)$. 
Citation: Iyigun T, Kyaruzi MM, Reyhancan A, Timur B, Kaya M, et al. (2018) Does Age Matter in Elder Patients Over 80 Years Undergoing Coronary Artery Bypass Grafting. J Cardiovasc Dis Diagn 6: 329. doi:10.4172/2329-9517.1000329

Page 4 of 8

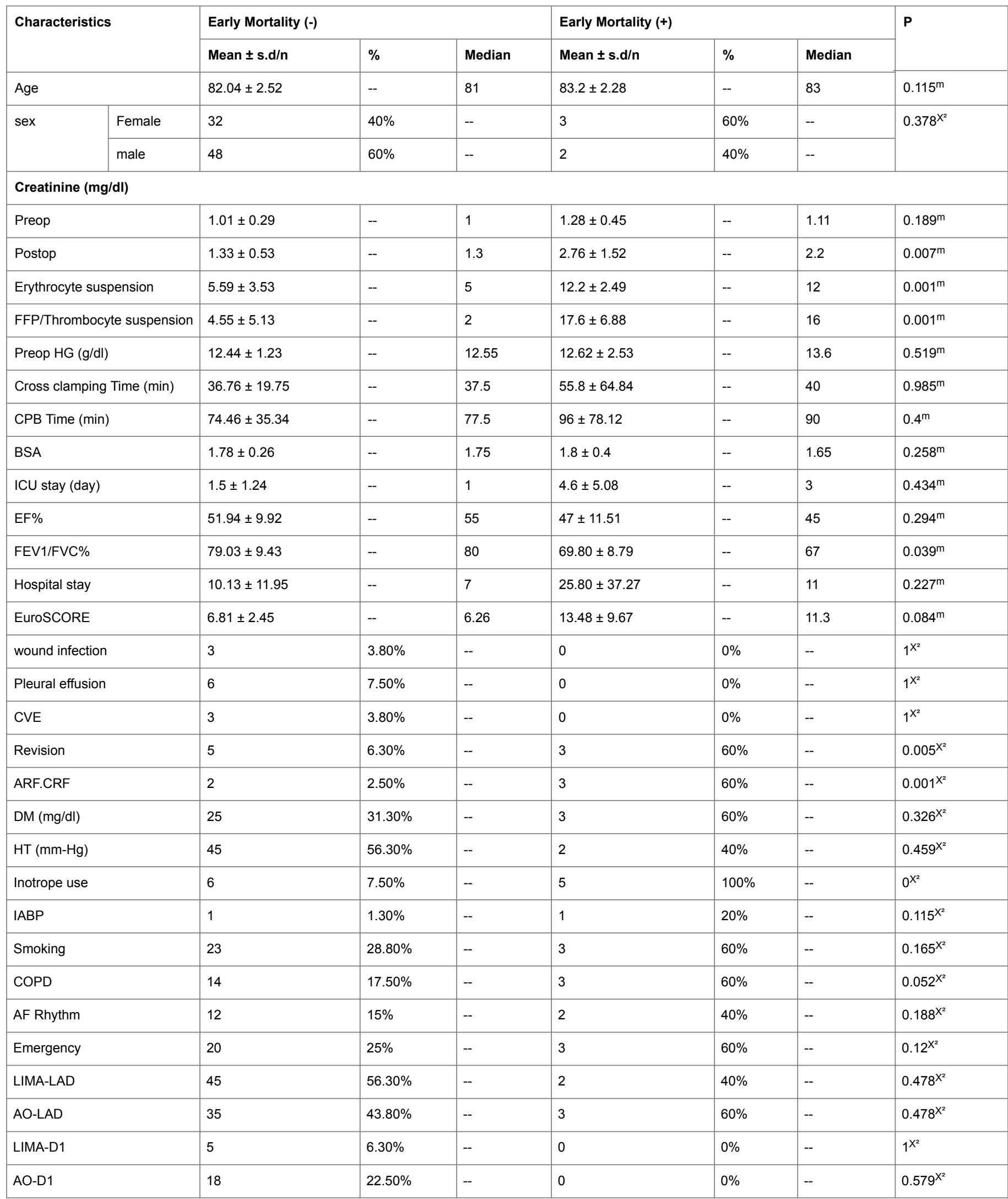


Citation: Iyigun T, Kyaruzi MM, Reyhancan A, Timur B, Kaya M, et al. (2018) Does Age Matter in Elder Patients Over 80 Years Undergoing Coronary Artery Bypass Grafting. J Cardiovasc Dis Diagn 6: 329. doi:10.4172/2329-9517.1000329

Page 5 of 8

\begin{tabular}{|c|c|c|c|c|c|c|c|}
\hline AO-D2 & 4 & $5 \%$ & -- & 0 & $0 \%$ & -- & $1^{x^{2}}$ \\
\hline AO-IM & 9 & $11.30 \%$ & -- & 0 & $0 \%$ & -- & $1^{x^{2}}$ \\
\hline AO-OM1 & 40 & $50 \%$ & -- & 2 & $40 \%$ & -- & $0.664^{x^{2}}$ \\
\hline AO-OM2 & 19 & $23.80 \%$ & -- & 0 & $0 \%$ & -- & $0.583^{x^{2}}$ \\
\hline $\mathrm{AO}-\mathrm{CX}$ & 2 & $2.50 \%$ & -- & 0 & $0 \%$ & -- & $1^{x^{2}}$ \\
\hline AO-RCA & 18 & $22.50 \%$ & -- & 0 & $0 \%$ & -- & $0.579^{x^{2}}$ \\
\hline AO-PL & 7 & $8.80 \%$ & -- & 1 & $20 \%$ & -- & $0.398^{x^{2}}$ \\
\hline AO-PD & 41 & $51.30 \%$ & -- & 4 & $80 \%$ & -- & $0.211^{x^{2}}$ \\
\hline
\end{tabular}

Table 2: Shows rate of early mortality in our study population.

\begin{tabular}{|c|c|c|c|c|c|c|c|c|}
\hline \multicolumn{2}{|l|}{ Characteristics } & \multicolumn{3}{|l|}{ Mortality (-) } & \multicolumn{3}{|l|}{ Mortality (+) } & \multirow[t]{2}{*}{$\mathbf{P}$} \\
\hline & & Mean $\pm s . d / n$ & $\%$ & Median & Mean \pm s.d/n & $\%$ & Median & \\
\hline \multicolumn{2}{|l|}{ Age } & $82.06 \pm 2.63$ & -- & 81 & $82.24 \pm 2.14$ & -- & 82 & $0.348^{m}$ \\
\hline \multirow[t]{2}{*}{ Sex } & Female & 29 & $45.30 \%$ & & 6 & $28.60 \%$ & -- & \multirow[t]{2}{*}{$0.176^{X^{2}}$} \\
\hline & Male & 35 & $54.70 \%$ & & 15 & $71.40 \%$ & -- & \\
\hline \multicolumn{9}{|c|}{ Creatinine (mg/dl) } \\
\hline \multicolumn{2}{|l|}{ Preop } & $0.97 \pm 0.28$ & -- & 0.91 & $1.2 \pm 0.3$ & -- & 1.11 & $0.003^{m}$ \\
\hline \multicolumn{2}{|l|}{ Postop } & $1.27 \pm 0.53$ & -- & 1.2 & $1.85 \pm 0.93$ & -- & 1.6 & $0^{\mathrm{m}}$ \\
\hline \multicolumn{2}{|c|}{ Erythrocyte suspension } & $5.3 \pm 3.46$ & -- & 5 & $8.05 \pm 4.12$ & -- & 7 & $0.005^{\mathrm{m}}$ \\
\hline \multicolumn{2}{|c|}{ FFP/Thrombocyte suspension } & $3.69 \pm 4.02$ & -- & 2 & $10.29 \pm 8.27$ & -- & 8 & $0^{m}$ \\
\hline \multicolumn{2}{|l|}{ Preop HG (g/dl) } & $12.35 \pm 1.3$ & -- & 12.5 & $12.77 \pm 1.37$ & -- & 12.8 & $0.17^{\mathrm{m}}$ \\
\hline \multicolumn{2}{|c|}{ Cross clamping Time (min) } & $36.52 \pm 18.51$ & -- & 37 & $42.05 \pm 36.94$ & -- & 40 & $0.748^{\mathrm{m}}$ \\
\hline \multicolumn{2}{|l|}{ CPB Time (min) } & $72.77 \pm 34.21$ & -- & 74.5 & $84.76 \pm 49.63$ & -- & 88 & $0.105^{\mathrm{m}}$ \\
\hline \multicolumn{2}{|l|}{ BSA } & $1.79 \pm 0.28$ & -- & 1.76 & $1.76 \pm 0.23$ & -- & 1.73 & $0.412^{m}$ \\
\hline \multicolumn{2}{|l|}{ ICU stay (day) } & $1.28 \pm 0.83$ & -- & 1 & $2.9 \pm 3.05$ & -- & 2 & $0.003^{m}$ \\
\hline \multicolumn{2}{|l|}{$\mathrm{EF} \%$} & $52.66 \pm 9.59$ & -- & 55 & $48.57 \pm 10.86$ & -- & 50 & $0.124^{\mathrm{m}}$ \\
\hline \multicolumn{2}{|l|}{ FEV1/FVC\% } & $78.20 \pm 9.03$ & -- & 80 & $79.33 \pm 11.36$ & -- & 79 & $0.935^{\mathrm{m}}$ \\
\hline \multicolumn{2}{|l|}{ Hospital stay } & $8.64 \pm 4.83$ & -- & 7 & $18.38 \pm 27.40$ & -- & 8 & $0.129^{m}$ \\
\hline \multicolumn{2}{|l|}{ EuroSCORE } & $6.8 \pm 2.37$ & -- & 6.26 & $8.44 \pm 5.75$ & -- & 6.96 & $0.531^{m}$ \\
\hline \multicolumn{2}{|l|}{ wound infection } & 2 & $3.1 \%$ & -- & 1 & $4.80 \%$ & -- & $0.724^{X^{2}}$ \\
\hline \multicolumn{2}{|l|}{ Pleural effusion } & 6 & $9.4 \%$ & -- & 0 & $0 \%$ & -- & $1^{X^{2}}$ \\
\hline \multicolumn{2}{|l|}{ CVE } & 2 & $3.1 \%$ & -- & 1 & $4.80 \%$ & -- & $0.329^{X^{2}}$ \\
\hline \multicolumn{2}{|l|}{ Revision } & 2 & $3.1 \%$ & -- & 6 & $28.60 \%$ & -- & $0.001^{X^{2}}$ \\
\hline \multicolumn{2}{|l|}{ ARF.CRF } & 0 & $0 \%$ & -- & 5 & $23.80 \%$ & -- & $0.001^{x^{2}}$ \\
\hline \multicolumn{2}{|l|}{$\mathrm{DM}(\mathrm{mg} / \mathrm{dl})$} & 19 & $29.7 \%$ & -- & 9 & $42.90 \%$ & -- & $0.265^{\mathrm{X}^{2}}$ \\
\hline
\end{tabular}


Citation: Iyigun T, Kyaruzi MM, Reyhancan A, Timur B, Kaya M, et al. (2018) Does Age Matter in Elder Patients Over 80 Years Undergoing Coronary Artery Bypass Grafting. J Cardiovasc Dis Diagn 6: 329. doi:10.4172/2329-9517.1000329

Page 6 of 8

\begin{tabular}{|c|c|c|c|c|c|c|c|}
\hline $\mathrm{HT}(\mathrm{mm}-\mathrm{Hg})$ & 34 & $53.1 \%$ & -- & 13 & $61.90 \%$ & -- & $0.526^{X^{2}}$ \\
\hline Inotrope use & 2 & $3.1 \%$ & -- & 9 & $42.90 \%$ & -- & $0^{x^{2}}$ \\
\hline IABP & 1 & $1.6 \%$ & -- & 1 & $4.80 \%$ & -- & $0.435^{X^{2}}$ \\
\hline Smoking & 17 & $26.6 \%$ & -- & 9 & $42.90 \%$ & -- & $0.16^{\mathrm{X}^{2}}$ \\
\hline COPD & 13 & $20.3 \%$ & -- & 4 & $19 \%$ & -- & $0.9^{\mathrm{X}^{2}}$ \\
\hline AF Rhythm & 8 & $12.5 \%$ & -- & 6 & $28.60 \%$ & -- & $0.085^{x^{2}}$ \\
\hline Emergency & 15 & $23.4 \%$ & -- & 8 & $38.10 \%$ & -- & $0.19^{X^{2}}$ \\
\hline LIMA-LAD & 39 & $60.9 \%$ & -- & 8 & $38.10 \%$ & -- & $0.068^{X^{2}}$ \\
\hline AO-LAD & 25 & $39.1 \%$ & -- & 13 & $61.90 \%$ & -- & $0.068^{X^{2}}$ \\
\hline LIMA-D1 & 5 & $7.8 \%$ & -- & 0 & $0 \%$ & -- & $0.326^{\mathrm{X}^{2}}$ \\
\hline AO-D1 & 12 & $18.8 \%$ & -- & 6 & $28.60 \%$ & -- & $0.339^{X^{2}}$ \\
\hline AO-D2 & 3 & $4.7 \%$ & -- & 1 & $4.80 \%$ & -- & $1^{X^{2}}$ \\
\hline AO-IM & 5 & $7.8 \%$ & -- & 4 & $19 \%$ & -- & $0.147^{X^{2}}$ \\
\hline AO-OM1 & 35 & $54.7 \%$ & -- & 7 & $33.30 \%$ & -- & $0.089^{X^{2}}$ \\
\hline AO-OM2 & 12 & $18.8 \%$ & -- & 7 & $33.30 \%$ & -- & $0.164^{X^{2}}$ \\
\hline AO-CX & 2 & $3.1 \%$ & -- & 0 & $0 \%$ & -- & $1^{X^{2}}$ \\
\hline AO-RCA & 13 & $20.3 \%$ & -- & 5 & $23.80 \%$ & -- & $0.734^{X^{2}}$ \\
\hline AO-PL & 6 & $9.4 \%$ & -- & 2 & $9.50 \%$ & -- & $0.934^{X^{2}}$ \\
\hline AO-PD & 34 & $53.1 \%$ & -- & 11 & $52.40 \%$ & -- & $0.953^{x^{2}}$ \\
\hline
\end{tabular}

Table 3: Shows rate of mortality in our study population.

In the univariate model, creatinine erythrocyte suspension, plasma/ platelet suspension, revision, inotropic use of the dead and living patients were significant $(\mathrm{p}<0.05)$. In the multivariate model, significant and independent $(\mathrm{p}<0.05)$ efficacy of inotropes was observed at the distinction of dead and living patients (Table 4).

\begin{tabular}{|l|l|l|l|l|l|l|}
\hline \multirow{2}{*}{ Characteristic } & \multicolumn{2}{l}{} & \multicolumn{3}{l|}{ Multivariable Model } \\
\cline { 2 - 8 } & OR & \% 95 GA & p & OR & \% 95 GA & p \\
\hline Creatinine & 3.5 & $1.41-8.68$ & 0.007 & -- & -- & - \\
\hline Erythrocyte suspension & 1.2 & $1.05-1.37$ & 0.008 & -- & -- & - \\
\hline FFP/Thrombocyte suspension & 1.19 & $1.08-1.32$ & 0 & -- & -- & - \\
\hline Revision & 12.4 & $2.27-67.66$ & 0.004 & -- & -- & 0 \\
\hline Inotrope Use & 23.25 & $4.46-121.32$ & 0 & 23.25 & $4.46-121.32$ & \\
\hline Logistic Regression & & & & & \\
\hline
\end{tabular}

Table 4: Logistic regression modality.

\section{Discussion}

The number of patients suffering from coronary artery diseases in elder patients is increasing. Advancement of techniques increase in knowledge has made coronary artery bypass grafting to be done in standardized way in treatment of severe symptomatic coronary artery lesions. The population of patients diagnosed with coronary lesions referred for cardiac surgery has changed gradually. Low risk patients have been replaced with ageing who are associated with various comorbidities. 
Old age has been a determining factor in patients referred for revascularization since $\mathrm{CABG}$ has been indicated in patients with coronary lesions $[9,10]$. Advancement of operative techniques, reduced effects of the cardio-pulmonary bypass, and good postoperative care have constantly counterbalanced the obvious fragility of aged population. Thus, cardiac surgery turned out to be a gold Standard treatment even in patients with old age [11].

The increase in life expectancy has resulted into increase in old aged people associated with cardiovascular diseases especially patients with coronary lesions referred for CABG. Comorbidities associated with aging in candidates undergoing CABG are known for being worsening the clinical results and affecting mortality in elderly patients. Our study analyzed some of these risk factors from our clinical experience that are affecting mortality in elderly patients. These factors include compromised renal dysfunction, high frequency use of transfusion, history of CVE, diabetes mellitus, hypertension, etc.

Renal dysfunction is known factor that jeopardizes the CABG in elderly patients. Presence of previous renal dysfunction indicates the occurrence of ARF or CRF during postoperative period. In a retrospective analysis of 1,746 patients, including 155 patients in the 9th decade of life, Scott et al. [12] showed a 30-day mortality of $9 \%$ in the older group compared to $1.2 \%$ in the younger patients. Older patients had more complications including postoperative renal failure and neurological complications. In correlation with our study high level of creatinine preoperatively was significantly associated with postoperative early mortality.

Blood transfusion is another potent factor that largely affect the mortality in elder patients undergoing CABG. Considering that blood transfusion is regarded as an organ transplant which is limited or contraindicated in elder patients; blood transfusion may be associated with many risks such as pulmonary capacity decrease, ARF and many other organ dysfunctions. Our clinical study found out that patients who had massive blood transfusion were having a high early mortality compared to those who had minimal use of blood transfusion.

Early mortality was observed in five patients throughout the period of our study. The mortality rate throughout our study was 21 patients. Both renal dysfunction and blood transfusion were associated with early mortality and late mortality in our study (Tables 2 and 3). Patients who had revision also had increased mortality. Requirement of blood transfusion due to hemorrhage during revision may be a factor as to why these patients had high mortality. Also, these patients had prolonged hospital stay and ICU stay.

Our study had 28 (32.9\%) patients with DM (Table 1). These patients had DM type 2. All these patients were under oral antidiabetic drugs with regulated blood sugar. In our center, preoperatively all oral antidiabetic drugs were stopped, and insulin was started. During admission blood sugar were in normal ranges and all patients with DM received diabetic program course. We are also concerned with the issue of regulating blood sugars before surgical procedure. Our protocol involves regulating their blood sugars and stopping all antidiabetic drugs before operation. During perioperative period blood sugars are controlled under subcutaneous insulin. In our study DM has no significant difference on mortality between the groups.

Relevantly our study found no significant differences between the groups in other remarkable preoperative risk factors linked to cardiovascular or overall morbidity, such as the history of transient ischemic attack or stroke, hypertension (both showing a slight trend to higher incidence in the elderly), previous myocardial infarction, percutaneous coronary intervention or cardiac surgery, decreased ejection fraction, chronic obstructive pulmonary disease, and hypercholesterolemia. The vast number of these patients might have been referred for percutaneous coronary intervention rather than surgery.

\section{Conclusion}

Both early and late mortality rate in elder patients appears to be higher when preoperative creatinine levels are high and massive blood transfusion use during postoperative period of CABG. Assessment of these factors both preoperative and postoperatively would clearly help in setting a plan for their management that would decrease mortality in elder patients.

\section{Acknowledgements}

We would like to thank the surgical team and workers at our cardiovascular center.

\section{Conflict of Interest}

There is no any conflict of interest with any financial organization of interest regarding the material discussed in the manuscript.

\section{Authors contribution}

- Dr. Taner Iyigun: Project draft, analysis, writing.

- Dr. Mugisha Kyaruzi: Data collection, writing, editing.

- Dr. Adem Reyhancan: Data collection, advice during analysis.

- Dr. Bariş Timur: Data collection.

- Dr. Muzeyyen Iyigun: Editing, critical revision.

- Dr. Mehmet Kaya: Critical revision, approval.

\section{References}

1. Pietrzyk E, Michta K, Gorczyca-Michta I, Wożakowska-Kapłon B (2014) Coronary artery bypass grafting in patients over 80 years of age: A singlecentre experience. Kardiol Pol 72: 598-603.

2. Piątek J, Kędziora A, Kiełbasa G, Olszewska M, Sobczyk D, et al. (2017) How to predict the risk of postoperative complications after coronary artery bypass grafting in patients under 50 and over 80 years old. A retrospective cross-sectional study. Kardiol Pol 75: 975-982.

3. Lopez AD, Mathers CD (2006) Measuring the global burden of disease and epidemiological transitions: 2002-2030. Ann Trop Med Parasitol 100: 481-499.

4. World Population Ageing 1950-2050 (2006) Department of Economic and Social Affairs, New York.

5. Nashef SA, Roques F, Michel P, Gauducheau E, Lemeshow S, et al. (1999) European system for cardiac operative risk evaluation (EuroSCORE). Eur J Cardiothorac Surg 16: 9-13.

6. Michel P, Roques F, Nashef SA (2003) EuroSCORE project group: Logistic or additive EuroSCORE for high-risk patients? Eur J Cardiothorac Surg 23: 684-687.

7. Shahian DM, O'Brien SM, Filardo G, Ferraris VA, Haan CK, et al. (2009) The Society of Thoracic Surgeons 2008 cardiac surgery risk models: Part 1-coronary artery bypass grafting surgery. Ann Thorac Surg 88: 2-22.

8. Shapira I, Pines A, Mohr R (2001) Updated review of the coronary artery bypass grafting option in octogenarians: Good tidings. Am J Geriatr Cardiol 10: 199-204.

9. Mohan R, Amsel BJ, Walter PJ (1992) Coronary artery bypass grafting in the elderly: A review of studies on patients older than 64,69 or 74 years. Cardiology 80: 215-225. 
Citation: Iyigun T, Kyaruzi MM, Reyhancan A, Timur B, Kaya M, et al. (2018) Does Age Matter in Elder Patients Over 80 Years Undergoing Coronary Artery Bypass Grafting. J Cardiovasc Dis Diagn 6: 329. doi:10.4172/2329-9517.1000329

Page 8 of 8

10. Khan SS, Kupfer JM, Matloff JM, Tsai TP, Nessim S (1992) Interaction of age and preoperative risk factors in predicting operative mortality for coronary bypass surgery. Circulation 86: 186-190.

11. Alexander KP, Anstrom KJ, Muhlbaier LH, Grosswald RD, Smith PK, et al. (2000) Outcomes of cardiac surgery in patients $>$ or $=80$ years: Results from the National Cardiovascular Network. J Am Coll Cardiol 35: 731-738.
12. Scott BH, Seifert FC, Grimson R, Glass P (2005) Octogenarians undergoing coronary artery bypass graft surgery: Resource utilization, postoperative mortality, and morbidity. J Cardiothorac Vasc Anesthesia 19: 583-588. 